\title{
Efeito da palha e da mistura atrazine e metolachlor no controle de plantas daninhas na cultura do milho, em sistema de plantio direto ${ }^{(1)}$
}

\author{
Maurílio Fernandes de Oliveira( ${ }^{(2)}$, Ramon Costa Alvarenga ${ }^{(2)}$, Antônio Carlos de Oliveira( ${ }^{(2)}$ e José Carlos Cruz ${ }^{(2)}$
}

\begin{abstract}
Resumo - O objetivo deste trabalho foi estudar o efeito de níveis de palha de milho e da mistura formulada atrazine e metolachlor no controle de plantas daninhas na cultura de milho, em sistema de plantio direto. $\mathrm{O}$ ensaio foi realizado num Latossolo Vermelho-distrófico, argiloso, fase cerrado, sendo a dessecação do mato feita com glyphosate, 15 dias antes do plantio. O delineamento experimental utilizado foi o de blocos ao acaso, com parcelas subdivididas e com três repetições. Antes do plantio do milho, distribuíram-se cinco níveis de palha de milho $\left(0,3,6,9\right.$ e $\left.12 \mathrm{t} \mathrm{ha}^{-1}\right)$, nas parcelas, de modo uniforme. Nas subparcelas, após o plantio, foram considerados dois tratamentos referentes a herbicida: ausência de herbicida ou a dose de 6,0 $\mathrm{L} \mathrm{ha}^{-1}$ de atrazine, e metolachlor $\left(1.200+1.800 \mathrm{~g} \mathrm{ha}^{-1}\right)$. Avaliou-se o número das plantas daninhas, por espécie, aos 26 e 41 dias após o plantio. O número total de plantas daninhas foi reduzido significativamente pelos níveis de palha, independentemente da presença do herbicida e da época de avaliação. O herbicida não apresentou efeito significativo na primeira época de avaliação; entretanto, na segunda, a redução no número total de plantas daninhas foi de, aproximadamente, $53 \%$ em relação às parcelas que não o receberam. A população total de planta daninha foi significativamente superior na segunda avaliação, na ausência do herbicida. Na presença do herbicida, não houve diferença significativa na população total de invasoras entre as duas épocas de avaliação.
\end{abstract}

Termos para indexação: cobertura com palha, resíduos de colheita, herbicidas, sustentabilidade.

\section{Effect of corn plant residue and mixture of atrazine plus metolachlor on the weeds control in no-till corn system}

\begin{abstract}
The objective of this work was to study the effect of corn plant residue and mixture of atrazine plus metolachlor on weed control in no-till corn system. This experiment was performed in an Oxisol, and the weed desiccation was done using glyphosate, 15 days before planting. The experimental design was a randomized block, with three replications. Before corn planting, five levels of corn plant residues $\left(0,3,6,9 \mathrm{e} 12 \mathrm{tha}^{-1}\right)$ were equally distributed in the plots. Two treatments were applied in subplots after corn planting: one without herbicide and the other one using the commercial mixture of atrazine plus metolachlor $\left(1,200+1,800 \mathrm{~g} \mathrm{ha}^{-1}\right)$. Different weed species were evaluated, at 26 and 41 days after planting. The total grass weeds number was significantly affected by the plant residue levels, independently of herbicide treatments and of evaluation period. The herbicide did not show a significant effect in the first evaluation period. However, in the second evaluation period, the herbicide reduced about $53 \%$ the total number of weeds compared to the plots without herbicide. It was verified that in the herbicide absence the total population of weeds were significantly higher in the second evaluation period. However, in the herbicide presence there was no significant difference in the total population of weeds between the two evaluated periods.
\end{abstract}

Index terms: straw mulch, crop residue, herbicide, sustainability.

(1) Aceito para publicação em 30 de junho de 2000.

(2) Embrapa-Centro Nacional de Pesquisa de Milho e Sorgo, Caixa Postal 151, CEP 35701-970 Sete Lagoas, MG. E-mail:mafeol@cnpms.embrapa.br, ramon@cnpms.embrapa.br, oliveira@cnpms.embrapa.br, zecarlos@cnpms.embrapa.br

\section{Introdução}

Recentemente, têm aumentado as preocupações com a qualidade do meio ambiente. Isto se deve ao aumento da poluição, da erosão, das áreas degrada- 
das, do empobrecimento da população e do êxodo rural, e à redução das áreas de preservação ambiental, o que tem levado à busca de métodos alternativos mais racionais de exploração agrícola, ou seja, à adoção de uma agricultura sustentável. Para isto é necessário esforço voltado ao melhor manejo das operações de preparo do solo, adubação, plantio, e o uso racional de agroquímicos mediante o controle integrado de plantas daninhas, insetos e doenças.

A degradação do meio ambiente depende do manejo adotado do solo, da água e dos pesticidas utilizados na exploração agrícola. Um aspecto importante na conservação dos recursos naturais solo e água, está relacionado com a proteção da superfície do solo. A cobertura do solo com plantas (cobertura viva) ou com resíduos (cobertura morta) atua como o principal fator de proteção do solo contra o impacto das gotas de chuva (Levien et al., 1990). O aumento da porcentagem de cobertura da superfície do solo reduz a quantidade e a velocidade da enxurrada (Carvalho et al., 1990) e, conseqüentemente, diminui a erosão, avaliada pelas perdas de solo e de água (Amado et al., 1989). Além disso, o preparo do solo é a operação que mais diretamente afeta a sua desagregação e a manutenção dos restos vegetais na superfície, ou sua incorporação.

O plantio direto, que consiste na semeadura diretamente sobre a palhada da cultura anterior ou de plantas cultivadas para esse fim, além de plantas daninhas previamente dessecadas, apresenta-se como uma prática conservacionista. Diversos autores (Gerard et al., 1988; Derpsch et al., 1991; Cassel et al., 1995; Potter et al., 1995; Derpsch, 1997; Cabezas, 1998) mostram que essa prática apresenta uma série de vantagens em relação ao sistema convencional.

Associadas aos aspectos de proteção do solo, as coberturas mortas reduzem a densidade da população de plantas daninhas, segundo diversos autores citados por Fornarolli et al. (1998). Em culturas de verão como soja, feijão e milho, semeadas no sistema de plantio direto sobre coberturas mortas densas, de lenta decomposição e com ação alelopática, há possibilidade de se reduzir ou até mesmo dispensar o uso de herbicidas (Almeida, 1988). No entanto, muitos agricultores fazem exatamente o contrário; aumentam as doses dos herbicidas residuais em plan- tio direto, alegando que parte do produto fica retida na palha e não atinge o solo. Neste caso, evidentemente, está se desperdiçando produto, onerando o custo de produção e poluindo o ambiente (Rodrigues et al., 1998).

A aplicação de herbicidas de pré-emergência, como a mistura atrazine e metolachlor, recomendados para o plantio convencional, com solo bem preparado, livre de torrões e restos vegetais, tem sido feita em plantio direto onde há grande quantidade de cobertura morta. Neste caso, boa parte desses herbicidas é interceptada pela palhada (Fornarolli et al., 1998; Rodrigues et al., 1998). Segundo estes autores, alguns herbicidas são mais retidos que outros pelas coberturas mortas; tais diferenças podem estar ligadas principalmente a diferentes solubilidades e à pressão de vapor de cada herbicida, quantidades e origens das coberturas mortas e intensidades e épocas de ocorrência de chuvas após a aplicação desses produtos.

O coeficiente de partição octanol-água $\left(\mathrm{K}_{\mathrm{ow}}\right)$ refere-se à medida da intensidade da afinidade da molécula pela fase polar (representada pela água) e apolar (representada pelo 1-octanol). Por ser uma medida da lipofilicidade da molécula, essa propriedade está sendo utilizada como medida da interação entre herbicidas e material orgânico.

O objetivo do presente trabalho foi estudar o efeito da quantidade de palha em cobertura e da mistura de atrazine + metolachlor no controle de plantas daninhas na cultura do milho, em sistema de plantio direto.

\section{Material e Métodos}

O ensaio foi conduzido na área experimental da Embrapa-Centro Nacional de Pesquisa de Milho e Sorgo, no Município de Sete Lagoas, MG, no ano agrícola de 1998/99, em um Latossolo Vermelho-distrófico, argiloso, fase cerrado, após cinco anos de ensaio com milho em sistema de plantio direto. A dessecação das plantas daninhas foi realizada com $3 \mathrm{~L} \mathrm{ha}^{-1}$ de glyphosate $\left(360 \mathrm{~g} \mathrm{~L}^{-1}\right)$, aproximadamente 15 dias antes do plantio de milho.

O delineamento experimental utilizado foi o de blocos ao acaso, com parcelas subdivididas e com três repetições. Antes do plantio do milho, distribuíram-se de modo uniforme cinco níveis de palha de milho $\left(0,3,6,9 \mathrm{e} 12 \mathrm{t} \mathrm{ha}^{-1}\right)$, nas parcelas de dimensões de 7,2 x 5,0 m, com 8 fileiras 
de milho. Nas subparcelas, após o plantio, foram considerados dois tratamentos referentes a herbicida: ausência de herbicida ou a dose de $6 \mathrm{~L} \mathrm{ha}^{-1}$ da mistura atrazine + metolachlor $\left(200+300 \mathrm{~g} \mathrm{~L}^{-1}\right)$.

A cultivar de milho BR 3123 foi semeada no dia 25 de novembro de 1998, utilizando-se plantadeira-adubadeira com espaçamento de 0,9 m entre linhas e densidade de 50 mil plantas por hectare, aplicando-se $300 \mathrm{~kg} \mathrm{ha}^{-1}$ do adubo formulado 4-30-16 + Zn. A aplicação dos herbicidas foi feita um dia após o plantio, utilizando pulverizador acoplado à tomada de força do trator, com velocidade de $4,5 \mathrm{~km} \mathrm{~h}^{-1}$ e rotação de $1.200 \mathrm{rpm}$, munido com barra de $12 \mathrm{~m}$, contendo 24 bicos Teejet 110.03, a uma altura de $50 \mathrm{~cm}$ do solo, vazão de $300 \mathrm{~L} \mathrm{ha}^{-1}$ e pressão de 50 libras pol-2.

A avaliação do número das plantas daninhas, por espécie, foi realizada em áreas de amostragem de $3 \mathrm{~m}^{2}$ marcadas ao acaso em cada unidade experimental. As avaliações foram realizadas em 21/12/1998 e 5/1/1999, ou seja, aos 26 e 41 dias após o plantio (DAP). Após a análise de variância, foi feita a análise de regressão, considerando-se o efeito da quantidade de palha sobre o número de plantas daninhas.

\section{Resultados e Discussão}

As principais plantas daninhas na área experimental foram: capim-colchão (Digitaria horizontalis), timbete (Cenchrus echinatus), capim-marmelada (Brachiaria plantaginea), rabo-de-raposa (Setaria geniculata), corda-de-viola (Ipomoea spp.), leiteira (Euphorbia spp.), poaia-branca (Richardia brasiliensis), picão-preto (Bidens pilosa) e mentrasto (Ageratum conyzoides). As gramíneas foram as principais infestantes da área experimental, tendo o capim-colchão e o timbete como espécies predominantes (Tabela 1).

A população de gramíneas invasoras foi afetada significativamente pelos níveis de palha, nas duas épocas de avaliação, tanto na ausência quanto na presença dos herbicidas. Na ausência dos herbicidas, para cada tonelada de palha adicionada, a estimativa de redução na infestação de gramíneas, transformada em porcentagem, ficou em torno de $6,4 \%$, na primeira avaliação, e 4,2\%, na segunda (Figura 1). Na presença do herbicida, a redução da população de gramíneas ficou em torno de $7,4 \%$ na primeira, e $6,0 \%$ na segunda. Esse fato demonstra que a cobertura morta afetou a emergência das gramíneas, independemente da aplicação do herbicida. O menor efeito da mistura herbicida, em especial do metolachlor sobre a população de gramíneas pode ser atribuído, possivelmente, à sua retenção pela cobertura morta, impedindo sua ação sobre as plantas. Segundo Rodrigues \& Almeida (1998), a absorção do metolachlor ocorre principalmente pelo coleóptilo e hipocótilo das plântulas quando atravessam a camada de terra onde se encontra o produto. Por isso, segundo esses autores a aplicação desse herbicida

Tabela 1. Porcentagem de infestação de plantas daninhas por espécie e classe na cultura do milho. Sete Lagoas, MG, 1999.

\begin{tabular}{ccc}
\hline Classe $^{(1)} /$ espécie & $\begin{array}{c}\text { Número de } \\
\text { plantas por } \\
\text { parcela }\end{array}$ & $\begin{array}{c}\text { Infestação por } \\
\text { espécie }(\%)\end{array}$ \\
\hline Gramíneas & 910 & \\
Capim-colchão & 395 & 30,5 \\
Capim-timbete & 479 & 36,9 \\
Rabo-de-raposa & 17 & 1,3 \\
Capim-marmelada & 10 & 0,8 \\
Outras espécies ${ }^{(2)}$ & 10 & 0,8 \\
Folhas largas & 386 & \\
Corda-de-viola & 73 & 5,6 \\
Leiteira & 91 & 7,0 \\
Poaia-branca & 18 & 1,4 \\
Mentrasto & 59 & 4,5 \\
Picão & 45 & 3,5 \\
Outras espécies ${ }^{(2)}$ & 100 & 7,7 \\
\hline
\end{tabular}

(1) A infestação por gramíneas foi de 70,3\%, e por folhas largas, de $29,7 \%$. (2) Com menos de $1 \%$ de infestação.

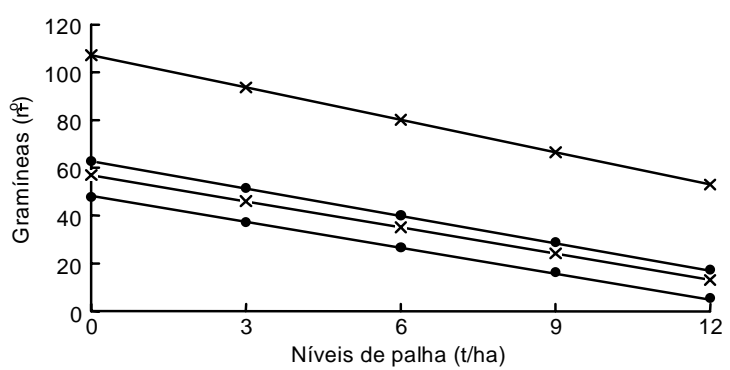

$\mathbf{X} \mathrm{Y}_{1}=57,04-3,65 \mathrm{P} ; \mathrm{R}^{2}=0,92 \quad \mathbf{X} \mathrm{Y}_{2}=107,14-4,51 \mathrm{P} ; \mathrm{R}^{2}=0,91$ $\begin{array}{lll}\mathrm{Y}_{1}=47,88-3,52 \mathrm{P} ; \mathrm{R}^{2}=0,77 & \bullet \mathrm{Y}_{2}=62,78-3,79 \mathrm{P} ; \mathrm{R}^{2}=0,85\end{array}$

Figura 1. Efeito da palha sobre a população de gramíneas, avaliada na ausência $(X)$ e na presença $(\bullet)$ de herbicida, aos 26 dias $\left(\mathrm{Y}_{1}\right)$ e 41 dias $\left(\mathrm{Y}_{2}\right)$ após o plantio, na cultura do milho. Sete Lagoas, MG, 1999. 
deve ser feita em solo bem preparado, livre de torrões e de restos de culturas e em boas condições de umidade, e é essencial que sua aplicação ocorra antes que as sementes alcancem um estado avançado de germinação. Além disso, a baixa precipitação ocorrida nos primeiros dias após aplicação do herbicida (Figura 2) pode não ter sido suficiente para sua remoção da palha, em particular do metolachlor, contribuindo para sua menor eficiência sobre a população de gramíneas (Rodrigues \& Almeida, citados por Rodrigues et al., 1998). Em razão disto, quando se adota o sistema de plantio direto pode-se esperar menor ação deste princípio ativo no controle de gramíneas.

Não se verificou efeito significativo dos níveis de palha sobre a população de folhas largas (Tabela 1). $O$ herbicida contribuiu significativamente para a redução das invasoras de folhas largas (de 29 para 10 plantas por $3 \mathrm{~m}^{2}$ ), independentemente do nível de palha e da época de avaliação. Esse fato deve-se à ação da atrazine, que apresenta controle de folhas largas. Estudos sobre a influência da cobertura morta no comportamento da atrazine demonstraram que a retenção desse herbicida pela palha de aveia $(4,5 \mathrm{e}$ $9,0 \mathrm{t} \mathrm{ha}^{-1}$ ) foi próxima a $85 \%$ da quantidade aplicada, para cada dose, não havendo diferença significativa entre os dois níveis de cobertura, e que após uma irrigação de $20 \mathrm{~mm}$ o atrazine foi lixiviado para o solo (Fornarolli et al., 1998).

A população total de plantas daninhas foi afetada significativamente pelos níveis de palha, independentemente da presença do herbicida e da época de avaliação (Figura 3). Para cada tonelada de palha adicionada, estima-se um controle de aproximadamente $4,0 \%$ no total de invasoras. O herbicida não apresentou efeito significativo na primeira época de avaliação; entretanto, na segunda, a redução na infestação total de invasoras pela aplicação do herbicida foi, aproximadamente, de 53\% em relação às parcelas que não o receberam (Tabela 2). Essa redução demonstra a importância da aplicação do produto, mesmo na presença de boa cobertura do solo em sistema de plantio direto, como forma de minimizar a concorrência das plantas daninhas com as plantas de milho. Na ausência de herbicida, verificou-se que a população total de invasoras foi significativamente superior na segunda avaliação. Essa maior popula- ção deve-se ao maior tempo para o seu estabelecimento e a ocorrência de chuvas (Figura 2). Concordando com Fornarolli et al. (1998) e Rodrigues et al. (1998), esses fatos demonstram também que o estudo da época de avaliação é importante, devendo ser considerados em ensaios dessa natureza. No entanto, na presença do herbicida, não houve diferença significativa na população total de plantas daninhas entre as duas épocas de avaliação.

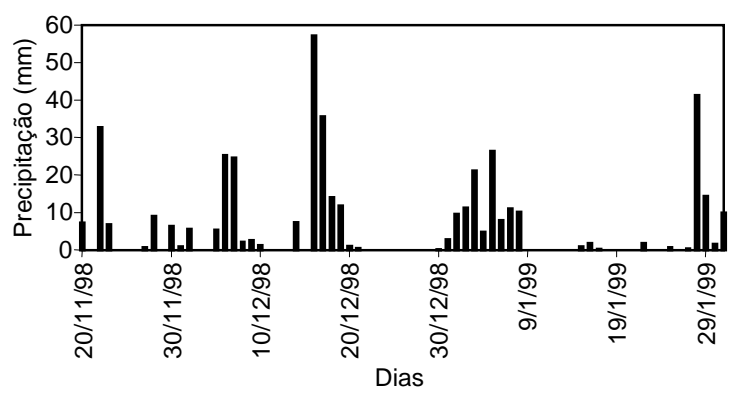

Figura 2. Precipitação diária ocorrida durante o período experimental de 1998/99. Sete Lagoas, MG, 1999.

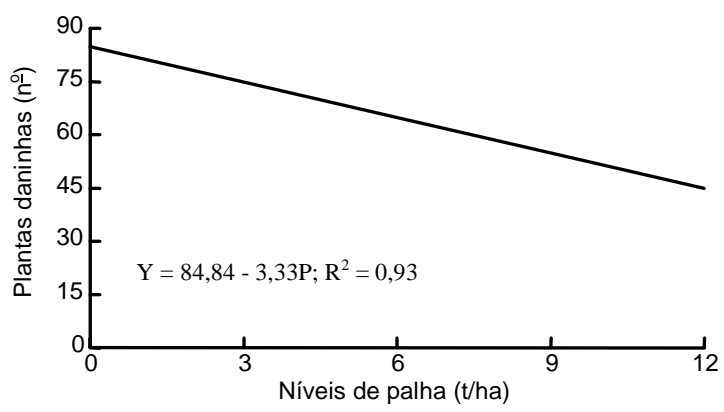

Figura 3. Efeito dos níveis de palha sobre o número total de plantas daninhas. Sete Lagoas, MG, 1999.

Tabela 2. Efeito do herbicida atrazine e metolachlor sobre o número total de plantas daninhas por $3 \mathrm{~m}^{2}$ na cultura do milho. Sete Lagoas, MG, $1999^{(1)}$.

\begin{tabular}{lcr}
\hline Herbicida & $26 \mathrm{DAP}^{(2)}$ & $41 \mathrm{DAP}$ \\
\hline Sem & $59 \mathrm{aB}$ & $114 \mathrm{aA}$ \\
Com & $33 \mathrm{aA}$ & $53 \mathrm{bA}$ \\
\hline
\end{tabular}

(1) Médias seguidas por mesma letra, minúscula na coluna e maiúscula na linha, não diferem estatisticamente entre si pelo teste Tukey a $5 \%$ de probabilidade. ${ }^{(2)}$ DAP: dias após o plantio. 
A diferença no controle das gramíneas e das folhas largas pode ser explicada pela retenção diferenciada dos herbicidas pela cobertura morta. Essa retenção pode ser atribuída à diferença nos valores de coeficiente de partição octanol-água dos produtos, maior para o metolachlor.

\section{Conclusões}

1. A utilização do herbicida atrazine e metolachlor reduz a população de invasoras, dependendo da época do ano.

2. O número de gramíneas é reduzido significativamente pelos níveis de palha, independentemente da presença de herbicida e da época do ano.

\section{Referências}

ALMEIDA, F. S. A alelopatia e as plantas. Londrina : IAPAR, 1988. 60 p. (IAPAR. Circular, 53).

AMADO, T. J. C.; COGO, N. P.; LEVIEN, R. Eficácia relativa do manejo de resíduo cultural de soja na redução das perdas de solo por erosão hídrica. Revista Brasileira de Ciência do Solo, Campinas, v. 13, p. 151-157, 1989.

CABEZAS, W. A. R. L. Comportamento de adubos nitrogenados em clima e solo de cerrado. Plantio Direto, Passo Fundo, n. 45, p. 52-60, maio/jun. 1998. Especial Cerrado.

CARVALHO, F. L. C.; COGO, N. P.; LEVIEN, R. Eficácia relativa de doses e formas de manejo de resíduo cultural de trigo na redução da erosão hídrica do solo. Revista Brasileira de Ciência do Solo, Campinas, v. 14, p. 227 234, 1990.

CASSEL, D. K.; RACZKOWSKI, C. W.; DENTON, H. P. Tillage effects on corn production and soil physical conditions. Soil Science Society of America Journal, Madison, v. 59, p. 1436-1443, 1995.
DERPSCH, R. Agricultura sustentável. In: SATURNINO, H. M.; LANDERS, J. N. (Ed.). O meio ambiente e o plantio direto. Goiânia : Embrapa, SPI, 1997. p. 29-48.

DERPSCH, R.; ROTH, C. H.; SIDIRAS, N.; KOPKE, U. Comparação entre diferentes métodos de preparo do solo. In: DERPSCH, R.; ROTH, C. H.; SIDIRAS, N.; KOPE, U. (Ed.). Controle da erosão no Paraná, Brasil: sistemas de cobertura do solo, plantio direto e preparo conservacionista do solo. Londrina : IAPAR/Deutsche Gesellschaft für Technische Zusammenarbeit, 1991.p. 71116.

FORNAROLLI, D. A.; RODRIGUES, B. N.; LIMA, J.; VALÉRIO, M. A. Influência da cobertura morta no comportamento do herbicida atrazine. Planta Daninha, Londrina, v. 16, n. 2, p. 97-107, 1998.

GERARD, C. J. U. P.; BORDOVSKY, D.; GERIK, T.; HONS, F.; MATOCHA, J. Conservation tillage effects on soil physical properties. HONS, F. (Ed.). Conservation tillage in Texas. College Station : Texas Agricultural Experiment Station, 1988. p. 16-28.

LEVIEN, R.; COGO, N. P.; ROCHENBACH, C. A. Erosão na cultura do milho em diferentes sistemas de cultivo anterior e métodos de preparo do solo. Revista Brasileira de Ciência do Solo, Campinas, v. 14, n. 1, p. 73-80, 1990.

POTTER, K. N.; TORBERT, H. A.; MORRISON JÚNIOR, J. E. Tillage and residue effects on infiltration and sediment losses on vertisols. Transactions of the ASAE, St. Joseph, v. 38, n. 5, p. 1414-1419, 1995.

RODRIGUes, B. N.; ALMEIDA, F. S. Guia de herbicidas. 4. ed. Londrina : IAPAR, 1998. 648 p.

RODRIGUES, B. N.; LIMA, J. de; YADA, I. F. U.; FORNAROLLI, D. A. Influência da cobertura morta no comportamento do herbicida trifluralin. Planta Daninha, Londrina, v. 16, n. 2, p. 163-173, 1998. 